\title{
Steam Turbines Produced by the Ural Turbine Works for Combined-Cycle Plants
}

\author{
A. E. Valamin ${ }^{a}$, A. Yu. Kultyshev ${ }^{a, b}$, T. L. Shibaev ${ }^{a}$, A. A. Gol'dberg ${ }^{a}$, V. N. Bilan ${ }^{a}$, \\ H. C. Paneque Aguilera ${ }^{a}$, Yu. A. Sakhnin ${ }^{a}$, M. V. Shekhter ${ }^{a}$, \\ M. Yu. Stepanov ${ }^{a}$, and E. N. Polyaeva ${ }^{a}$ \\ ${ }^{a}$ Ural Turbine Works, ul. Frontovykh Brigad 18, Yekaterinburg, 620017 Russia \\ ${ }^{b}$ Ural Federal University, ul. Mira 19, Yekaterinburg, 620002 Russia
}

\begin{abstract}
The most interesting and innovative solutions adopted in the projects of steam turbines for combined-cycle plants with capacities from 115 to $900 \mathrm{MW}$ are pointed out. The development of some ideas and components from the first projects to subsequent ones is shown.
\end{abstract}

Keywords: steam turbine, high-pressure cylinder, intermediate-pressure cylinder, low-pressure cylinder, combined stop and control valve, valve cluster, heat-recovery boiler

DOI: $10.1134 / \mathrm{S} 0040601513080120$

The authors of this article already presented reports and publications to the attention of public at large [15], in which the specific features of steam turbines intended for use in advanced projects of combinedcycle power plants (CCPs) were considered. We also gave a detailed description of the projects of prospective steam turbine that subsequently became real projects of cogeneration steam turbines for cogeneration stations (CSs) and district power stations under construction. In [6-10], the specific features of steam turbine designs, layout solutions, and basic process circuits of the turbine units developed by the Ural Turbine Works (UTZ) for CCPs were shown. In [4], it was pointed out that, in order to support the investment program aimed at development of the Russian power industry $[11,12]$ with relevant equipment, the Ministry of Power and Industry should work out and approve a series of standard sizes of modules comprising a gas turbine unit (GTU), a heat-recovery boiler (HRB), and a steam-turbine unit (STU) for construction of CCPs. This will make it possible not only to shorten the time taken to approve and implement power station construction projects, but also to reduce the customers' costs spent for procuring dedicated equipment manufactured under a single order.

We also pointed to the need to approve a series of standard sizes of main power-generating equipment, as a result of which Russian manufacturers will be able to reduce production costs and strongly compete with foreign vendors, and the personnel of power-generating enterprises will obtain modern serially produced and well-elaborated equipment [4].

In each new project of a turbine unit intended to serve as the steam part of a CCP, modern design and technological proposals were applied, the use of which makes it possible to solve a whole set of technical-economic, schematic, layout, and operational tasks with achieving high indicators of reliability and repairability of main and auxiliary power equipment.

In this article we would like to emphasize the most interesting and innovative solutions adopted in these projects and to show the development of some ideas and components from the first projects to subsequent ones.

\section{THE T-53/67-8.0 STEAM TURBINE FOR THE PGU-230 COMBINED-CYCLE PLANT}

The T-53/67-8.0 cogeneration steam turbine has been in operation since 2008 as part of the CCP installed at the Minsk TETs-3 cogeneration station, which comprises a 160-MW GT13E2 gas turbine produced by Alstom and a heat-recovery boiler produced in Slovakia.

The T-53/67-8.0 turbine is a two-cylinder machine developed on the basis of a serially produced Tp-115/125-12.8-1 turbine. The design of the T-53/67-8.0 turbine incorporates both well-elaborated solutions and fundamentally new ones, the latter connected primary with the fact that this turbine was designed to operate as part of a CCP [6].

The use of a throttle steam admission system in the turbine generated the need to design a new external valve cluster. Such a solution made it possible not only to exclude the cam distribution device from the construction, which has insufficient reliability, but also to obtain a uniform field of velocities upstream of the tur- 


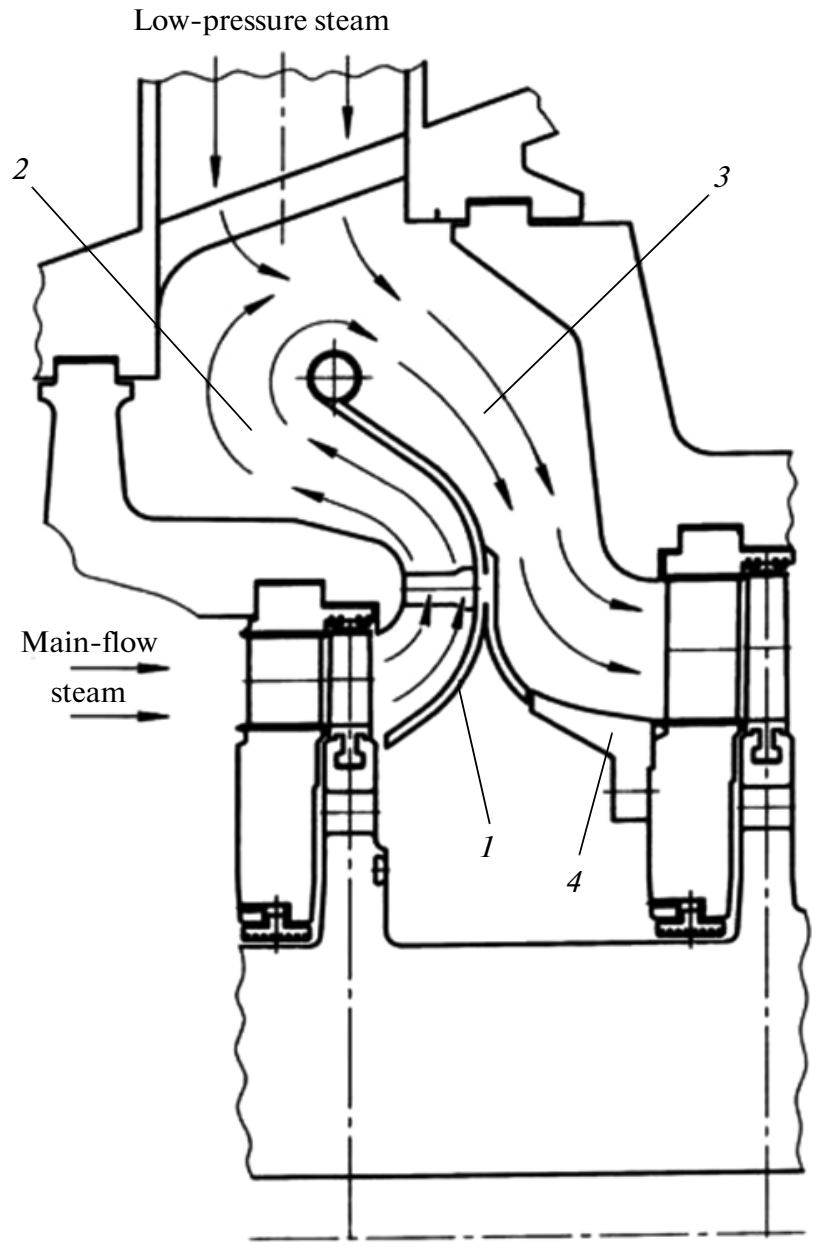

Fig. 1. Scheme of admitting low-pressure steam into the annular chamber with a curvilinear partition. (1) Curvilinear partition, (2) channel formed by the first yoke, its last stage, and the partition concave part, (3) channel formed by the yoke downstream of the chamber and the partition convex part, and (4) guide vane.

bine first stage during operation on partial loads by feeding steam to diametrically opposite sockets.

High-pressure steam from the HRB is supplied from the valve cluster consisting of a stop valve with an automatic lock and two control valves driven by their own servomotors to the high-pressure cylinder (HPC) casing via four pipelines arranged symmetrically in groups by two on the bottom and top [6].

Thus, the HPC is made without a control stage and, accordingly, without the massive disk of a control stage, due to which the turbine has enhanced reliability and better maneuverability. The use of a throttle steam admission system in the turbine also generated the need to elaborate a few design versions of the steam admission assembly for achieving a uniform field of velocities in the circumferential and axial directions at the inlet to the first stage. Three-dimensional gas flow was simulated with the use of structured hexagonal grids $(100 \%)$ with a denser pattern in the wall region.
As a result of numerical optimization, we obtained geometrical characteristics of the steam admission assembly with steam supplied to a common chamber, which has the minimal pressure drop with uniform distribution of both velocity and pressure fields at the inlet to the first stage.

Low-pressure steam from the HRB is supplied to the low-pressure cylinder's (LPC) annular chamber [13] via two clusters of combined low-pressure stop and control valves.

The annular chamber (Fig. 1) includes the following elements (Fig. 1):

(i) curvilinear partition 1 attached to the yoke upstream of the chamber, which divides the chamber into two parts;

(ii) channel 2 formed by the first yoke, its last stage, and the partition concave part for turning the steam flow in the flow path almost through $180^{\circ}$; and

(iii) channel 3 formed by the casing downstream of the chamber and the partition convex part for supplying mixed flow of steam to the stage downstream of the low-pressure loop steam admission chamber.

Guiding element 4 is installed on the curvilinear partition's convex part near the inlet of mixed steam flow to the stage.

Owing to an intricate trajectory along which steam passes through the flow path with turning through almost $180^{\circ}$, good mixing of this steam with the steam flow from the external source, uniform temperature of the mixed flow, and uniform density of this flow from the channel outlet are obtained. With such solution, it becomes possible to make a reliable turbine blade system with the low-pressure loop steam supplied from the external source into the flow path chamber.

\section{THE T-63/76-8.8 STEAM TURBINE FOR THE PGU-230 COMBINED-CYCLE PLANT}

The T-63/76-8.8 cogeneration steam turbine (Fig. 2) fitted with two heating extractions is intended to operate as part of the PGU-230 combined-cycle plant together with a GTE-160-4(7) gas turbine produced by the Leningrad Metal Works (LMZ) or with a V94.2A gas turbine produced by Siemens and a heatrecovery boiler produced by EMAl'yans. Projects of this CCP have been developed for the Izhevsk TETs-1, Vladimir TETs-2, Novobogoslovsk, and Kirov TETs-3 cogeneration stations.

The T-63/76-8.8 turbine is a single-cylinder machine with a two-casing cylinder and a loop-type scheme of steam motion in the cylinder [7]. The turbine cylinder has a cast inner casing and a welded outer casing. The outer casing is formed by means of an axially symmetrical end-face wall from stamped elliptical bottoms and a cylindrical barrel. The exact axial symmetry of the casing is disturbed by two flanges of the horizontal joint (the number $\times$ width $\times$ height $=$ 


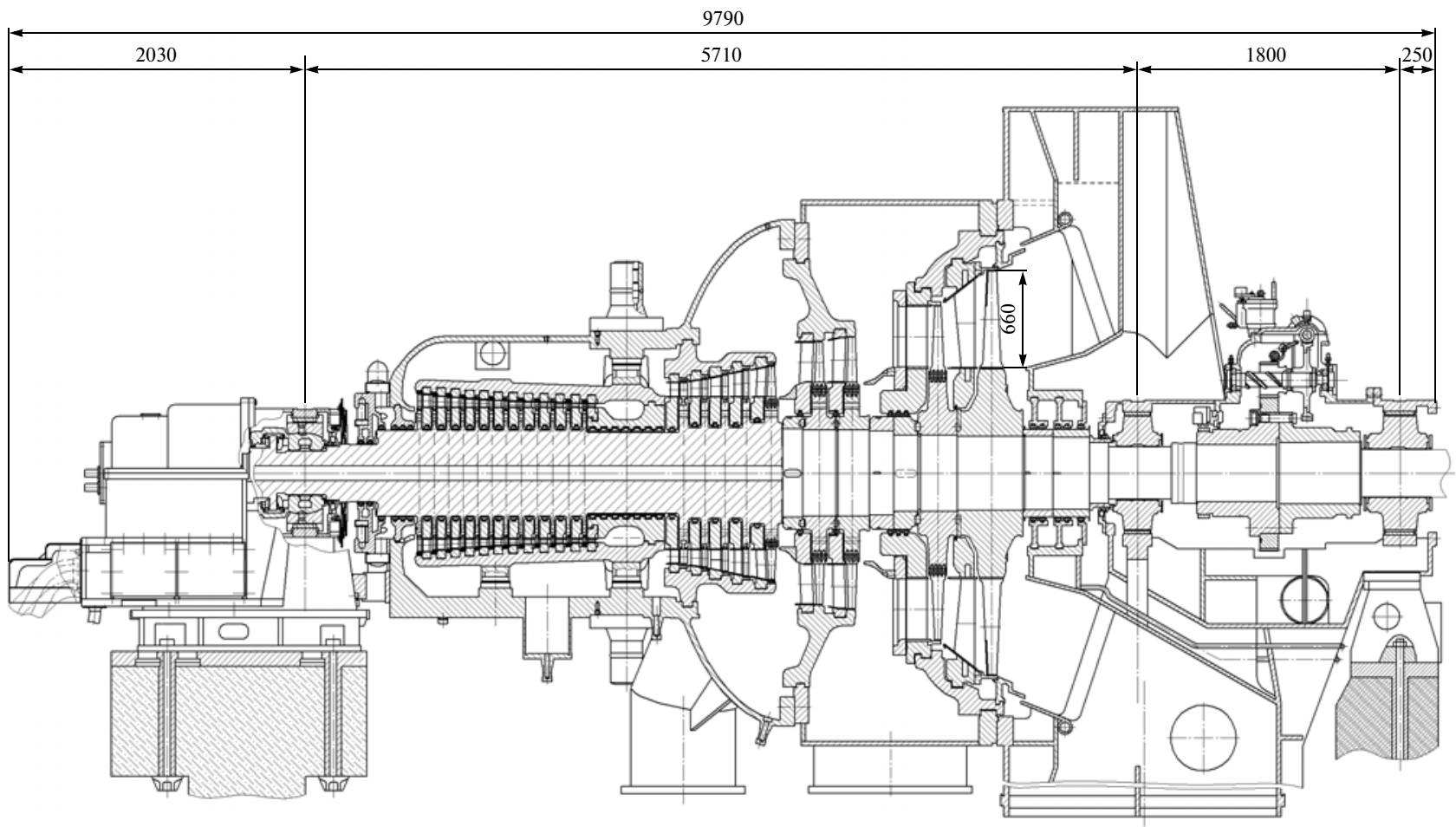

Fig. 2. The T-63/76-8.8 steam turbine.

$2 \times 100 \times 80 \mathrm{~mm})$ and by a so-called "board" $(150 \times$ $400 \mathrm{~mm}$ ) made for installing longitudinal keys in the casing lower half. With such a design, a smaller sag of the cylinder casing under its own weight is obtained in the initial stage of starting the turbine from the cold state owing to a faster heating of the upper half, after which it returns to the initial state, which may change insignificantly as the temperature of low-pressure loop steam varies in the range $295-320^{\circ} \mathrm{C}$.

The distinguishing feature of this turbine and the power unit as a whole is that an increased nominal pressure of low-pressure steam is used in it, which is equal to 1.4 MPa instead of the often used level equal to $0.5-0.7 \mathrm{MPa}$. This solution has been agreed upon with the customer, general designer, and HRB manufacturer.

Low-pressure steam of increased nominal pressure supplied from the HRB is admitted to the space between the turbine cylinder casings via one (instead of two) combined low-pressure stop and control valve (LP SCV), which comprises a control and a stop valve placed one inside the other and resting on the same seat.

It should be pointed out that with using LP steam of increased nominal pressure and a single-cylinder cogeneration steam turbine for the CCP of the described design, it becomes possible to solve the problem of making more than two controlled steam extractions in a single-cylinder turbine with a capacity of more than $60 \mathrm{MW}$, with a distance between their sockets sufficient for organizing these extractions.

The following positive features should be related to the technical-economic effect achieved from using such design of the turbine:

(i) The minimal axial distance is obtained between the turbine bearings for ensuring the strength and stiffness of its rotor. With such design, the conditions of a permissible static rotor sag $(0.42<0.50 \mathrm{~mm})$ are fulfilled, and smaller stresses arising in the rotor are obtained with the turbine capacity higher than $60 \mathrm{MW}$ by shortening the axial size, which is decreased as compared with the case of using a straight-flow steam motion scheme in the cylinder. Smaller leaks of LP steam are obtained as compared with leaks of highpressure steam in the straight-flow scheme owing to the use of a front end seal. The axial size of intermediate seal has been decreased to the sizes of high-pressure steam admission. The use of intermediate seal makes it possible to decrease leaks of high-pressure steam into the chamber upstream of the stages of the intermediate-pressure part (IPP) with the LP pressure equal to around 1.3-1.5 MPa instead of the frequently used level equal to $0.6-0.7 \mathrm{MPa}$, due to which smaller leaks are obtained with the same length of intermediate seal and with the same gap gap between the intermediate seal and rotor.

(ii) Simple implementation of the economically optimal IPP stages outside the inner casing is achieved. 
(iii) Better maneuverability of the turbine is achieved due to a shorter period of time taken for heating the inner casing, which is obtained due to decreasing the following parameters:

the casing length and thickness;

the difference of temperatures of steam passing through the high-pressure part (HPP) stages inside the casing and washing it in the intercasing space chamber.

(iv) The possibility is available to organize steam extraction for process needs with the parameters of the LP circuit both directly from the HRB and, if a larger flowrate is required, from the space between the casings of the steam turbine cylinder. A socket is available in the cylinder casing for organizing uncontrolled extraction of steam from the space between casings for production purposes. A controlled steam extraction can also be organized by installing a rotary cylindrical control diaphragm upstream of the 13th stage. No additional axial distance will be required for making this diaphragm, due to which there is no need to increase the axial distance between the bearings.

(v) The axial force exerted by the blades in the HPP and IPP stages, in the intermediate compartment between the heating extractions, and in the low-pressure part (LPP) is relieved in the optimal manner.

\section{THE T-40/50-8.8 STEAM TURBINE FOR THE PGU-115 COMBINED-CYCLE PLANT}

The $\mathrm{T}-40 / 50-8.8$ cogeneration steam turbine is intended to operate as part of the PGU-115 combined-cycle plant jointly with a PG 6111 FA gas turbine produced by General Electric and a heatrecovery boiler produced by EMAl'yans, and drives a TF-50-2UZ alternator produced by NPO Elsib.

The T-40/50-8.8 turbine is a single-cylinder twocasing machine with a loop-shaped steam motion scheme in the cylinder [8]. The inner casing has a similar design with the inner casing of the T-63/76-8.8 turbine cylinder. Owing to its well-elaborated and optimized design and the use of a loop-shaped steam flow scheme, the T-40/50-8.8 turbine, as the T-63/76-8.8 turbine, features a short period of time taken for heating it from the cold stage and high maneuverability indicators.

One of specific design features of this turbine is that it uses an original solution for admitting LP steam (Fig. 3a). The LP steam admission system comprises an annual header formed by the cylinder casing and a mixing device installed in the chamber of the turbine flow path. The mixing device is made in the form of two barrels between which profiled "sleeves" with slit cuts are installed (Fig. 3b). Low-pressure steam, the pressure of which is somewhat higher than the pressure of main steam flow in this flow path zone, moves through the "sleeves" from the supply chamber periphery to the root zone, goes out through the slit cuts, and mixes with the main flow, which washes the "sleeves", after which the resulting flow is forwarded to the next stage. Such a mixing device has a smaller axial size and makes it possible to save $200 \mathrm{~mm}$ as compared with the annular chamber containing a curvilinear partition (see Fig. 1). Under the conditions of the limiting axial distance between the turbine bearings, such a solution makes it possible to install an additional stage.

\section{THE Tp-35/40-8.8 STEAM TURBINE FOR A COMBINED-CYCLE PLANT}

The Tp-35/40-8.8 steam turbine developed for the Novokuibyshev TETs- 1 cogeneration station is a single-cylinder machine with steam extractions to heating and process headers [9]. The specific feature pertinent to the process circuit of this cogeneration station is that steam is admitted to the turbine from a common-station live steam header, which receives steam from the HRBs and steam boilers. In addition, the turbine receives LP steam from three HRBs. Low-pressure steam is supplied to two LP SCVs, after which it is fed via crossover pipes to the turbine flow path chamber, which contains a special device for mixing the main steam flow and LP, the design of which is similar to that used in the T-40/50-8.8 turbine (see Fig. 3).

The main specific features of the turbine unit equipped with the Tp-35/40-8.8 turbine lie in its layout solutions. One of them is that the turbine is placed in the existing turbine building of the Novokuibyshev CS on the place of a VPT-25-3 turbine, a circumstance that introduces certain constraints with respect to height elevations. One of these constraints is that the maximal lifting height of the bridge crane hook from the floor elevation of the turbine building condenser compartment is $+14.0 \mathrm{~m}$. The turbine set is installed on a pedestal, in which the existing pedestal plate of the dismantled turbine set with a top elevation of $1.8 \mathrm{~m}$ is used as the lower plate. Thus, the turbine set placement height is constrained on one hand by the crane hook lifting height and on the other hand by the height elevation of the existing pedestal lower plate. After elaborating a few versions, it was decided to make the turbine set maintenance platform at a height elevation of $+7.5 \mathrm{~m}$ and the condenser compartment floor at an elevation of $-0.5 \mathrm{~m}$.

Apart from the need to arrange the turbine in the existing turbine building, it should be noted that the space within the confines of the pedestal under the turbine cylinder is densely occupied by various kinds of pipelines, including the traditional high-pressure steam crossover pipes, the suction pipeline from gland seals, low-pressure crossover pipes, process steam extraction lines, and steam extraction pipelines for district heating purposes. All these components are arranged within tight confines of the single-cylinder turbine pedestal. As a result, the turbine unit occupies a small space in height and in plan: the turbine set cell 


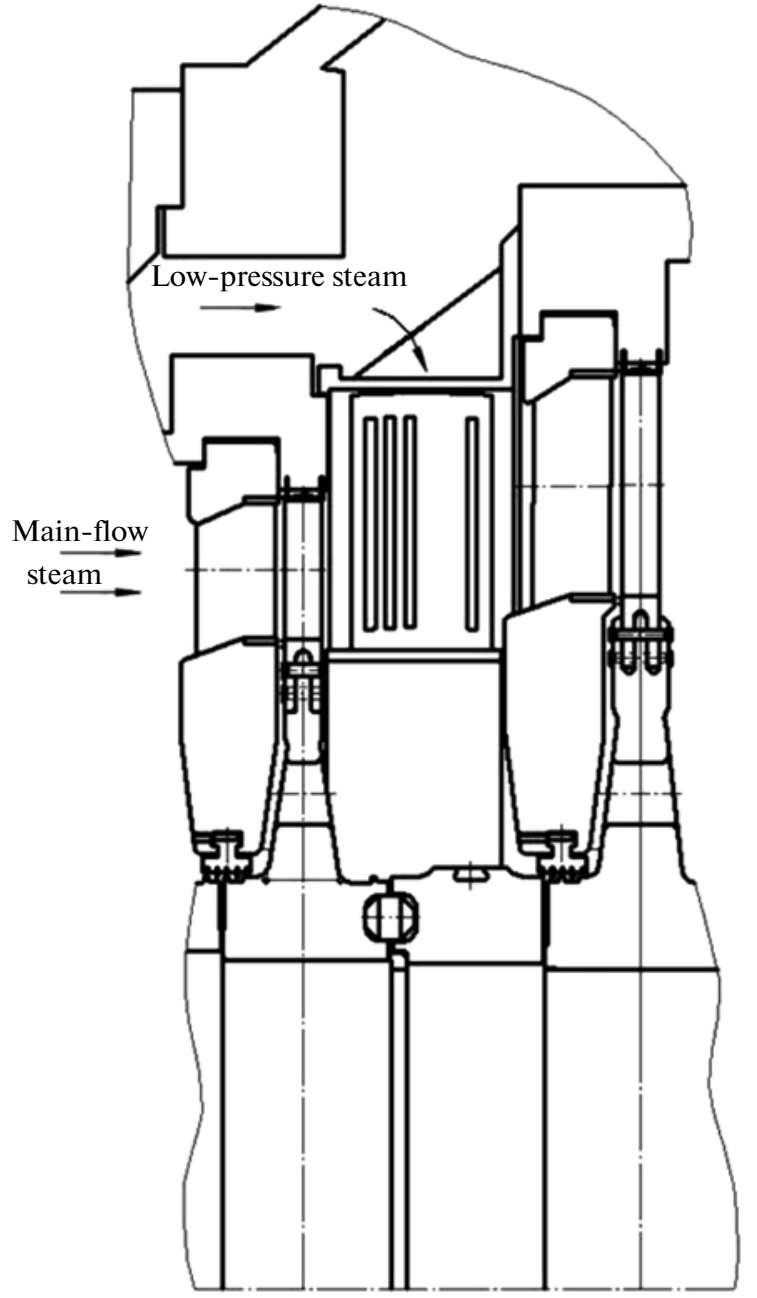

(a)

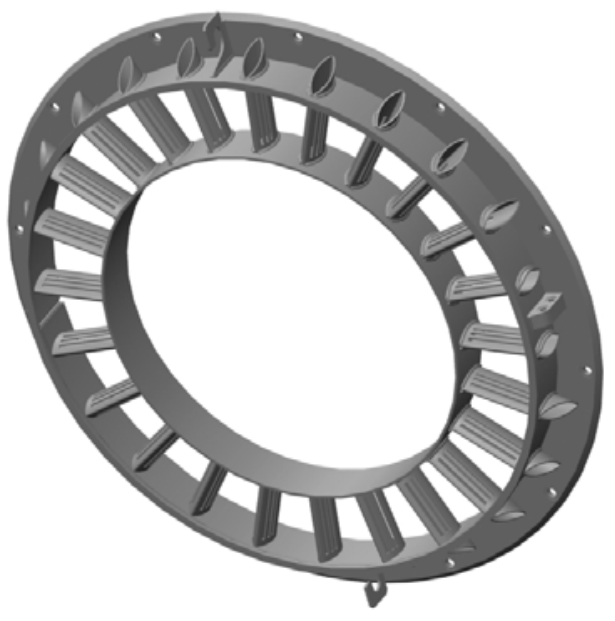

(b)

Fig. 3. Scheme of admitting low-pressure steam to the annular chamber with a mixing device. (a) Fragment of the flow path in the low-pressure steam admission zone and (b) mixing device.

has in-plan dimensions as small as $19 \times 24 \mathrm{~m}$. Thus, with regard of using the turbine building space, this layout project is among the most compact ones developed for arranging the turbine units produced by UTZ. It should be taken into account that the singlecylinder Tp-35/40-8.8 turbine is a two-loop one and has a large district heating extraction and an extraction for production purposes with a protection-and-control valve unit.

\section{THE T-113/145-12.4 STEAM TURBINE FOR THE PGU-410 COMBINED-CYCLE PLANT}

The $\mathrm{T}-113 / 145-12.4$ cogeneration steam turbine, a unique project developed for use as part of a PGU-410 combined-cycle plant, has been in operation at the Krasnodar CS since 2010. The CCP also includes the first in Russia 303-MW M701 F4 gas turbine produced by Mitsubishi Heavy Industries (MHI) and an HRB produced by EMAl'yans according to the project developed by the A\&E Company (Czech RepublicAustria).

The T-113/145-12.4 turbine is a three-cylinder machine with significantly new designs of its cylinders, which is mainly due to the fact that it was designed for operation as part of a three-loop CCP with steam reheating, and that it has high parameters of high-pressure steam [10].

The high-pressure cylinder (HPC) has a two-casing design with a straight-flow scheme of steam motion and with the two first stages separated in the inner casing. Such a solution guarantees the required strength and tightness at high pressure of steam in the steam admission chamber $p_{0}=11.9 \mathrm{MPa}$ and temperature $t_{0}=557^{\circ} \mathrm{C}$. The use of an inner casing opens the possibility not only to ensure the necessary tightness and strength of the casing, but also to keep high maneuvering parameters of the high-pressure cylinder as a whole. 

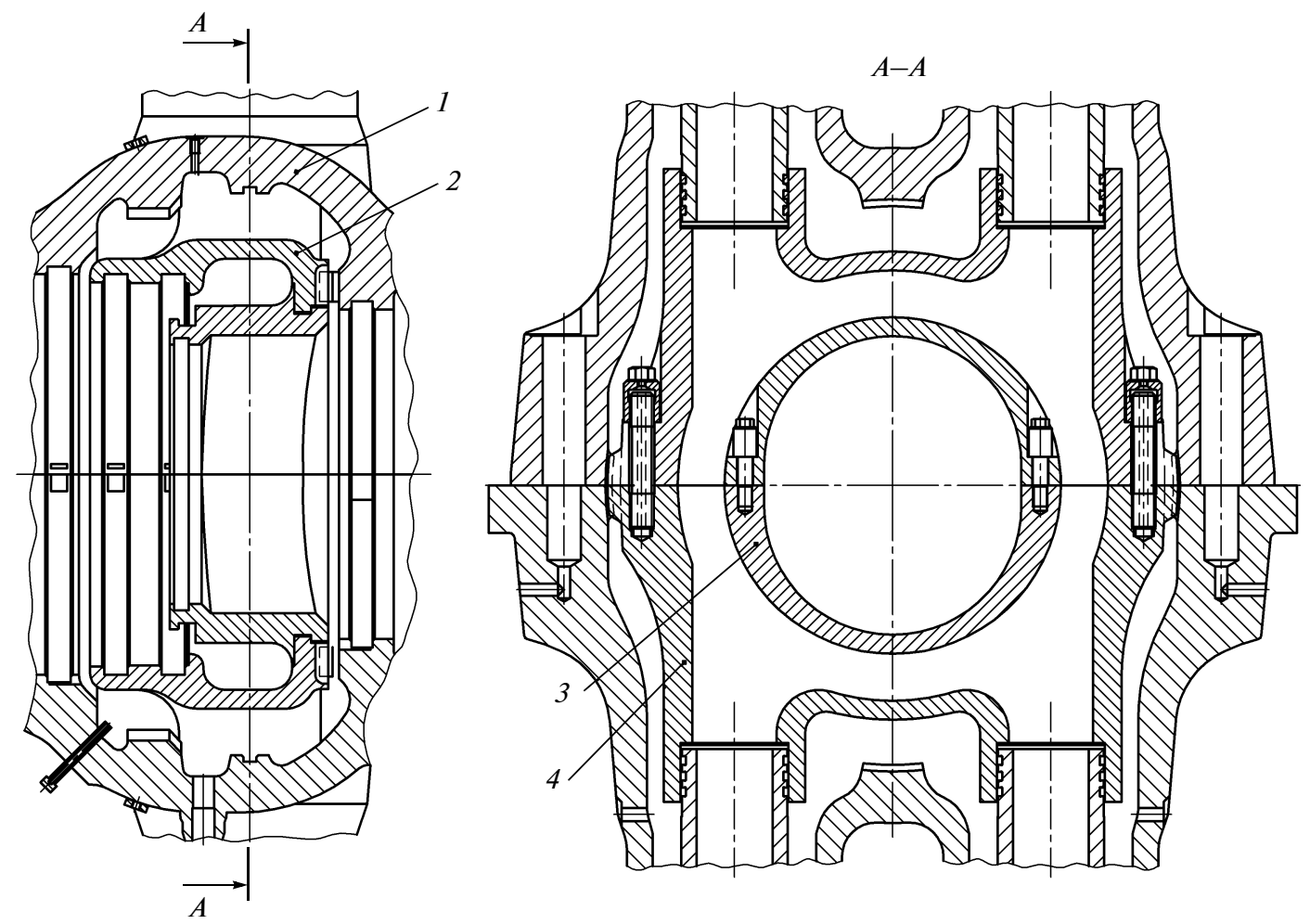

Fig. 4. Steam admission subsystem of the T-113/145-12.4 turbine HPC. (1) Outer casing, (2) inner casing, (3) inner cylinder lower generatrix (the forging), and (4) inner cylinder upper generatrix (the casting).

The inner casing has an original design (Fig. 4) and is assembled of a few parts, due to which it is well suited for casting and ensures the required tightness. The casing consists of a cast part, which includes the casing upper generatrix, steam admission sockets, and horizontal joint flanges, and a forged part serving as the casing lower generatrix. The main specific feature of the casing design is that the inner cylinder's horizontal joint is tightened not only in its outer (cast) part, but also in its inner (forged) part, due to which good tightness of the inner casing is achieved; i.e., leaks of steam over the horizontal joint are excluded. The inner part fasteners are installed on the side of steam space in special "pockets".

The intermediate-pressure cylinder (IPC) has a two-casing design with a loop scheme of steam motion in the flow path. The need of using such solution was mainly dictated by the fact that in this case the zone of elevated temperatures (the steam admission zone) is spaced at the maximal distance apart from the middle bearing. The design solutions used in the IPC inner casing are in principle similar to those described above for the HPC inner casing.

It should also be noted that the electrohydraulic control and protection system used in the T-113/14512.4 turbine differs very essentially from those used in the previously produced turbines: water is used as working fluid in this control and protection system, which is the most efficient fire protection measure.

\section{THE K-300-12.4 STEAM TURBINE FOR THE PGU-900 COMBINED-CYCLE PLANT}

UTZ specialists have worked out a draft design of the K-300-12.4 condensing steam turbine (Fig. 5) intended for use as part of the PGU-900 combinedcycle plant. Such CCP may also comprise two M701 F4 turbines produced by MHI or other turbines with a capacity of 300-375 MW. The turbine flow path was selected with reference to the following design parameters of steam supplied to the K-300-12.4 turbine:

Outdoor air temperature, ${ }^{\circ} \mathrm{C}$. $+15$

Parameters of steam upstream of the HPC:

pressure, MPa.

temperature, ${ }^{\circ} \mathrm{C}$ 562.6

flowrate, $\mathrm{t} / \mathrm{h}$.

Parameters of steam of the intermediate-pressure loop: pressure, $\mathrm{MPa}$. 3.26

temperature, ${ }^{\circ} \mathrm{C}$ 379

flowrate, $\mathrm{t} / \mathrm{h}$. 105.6

Parameters of steam upstream of the IPC: 


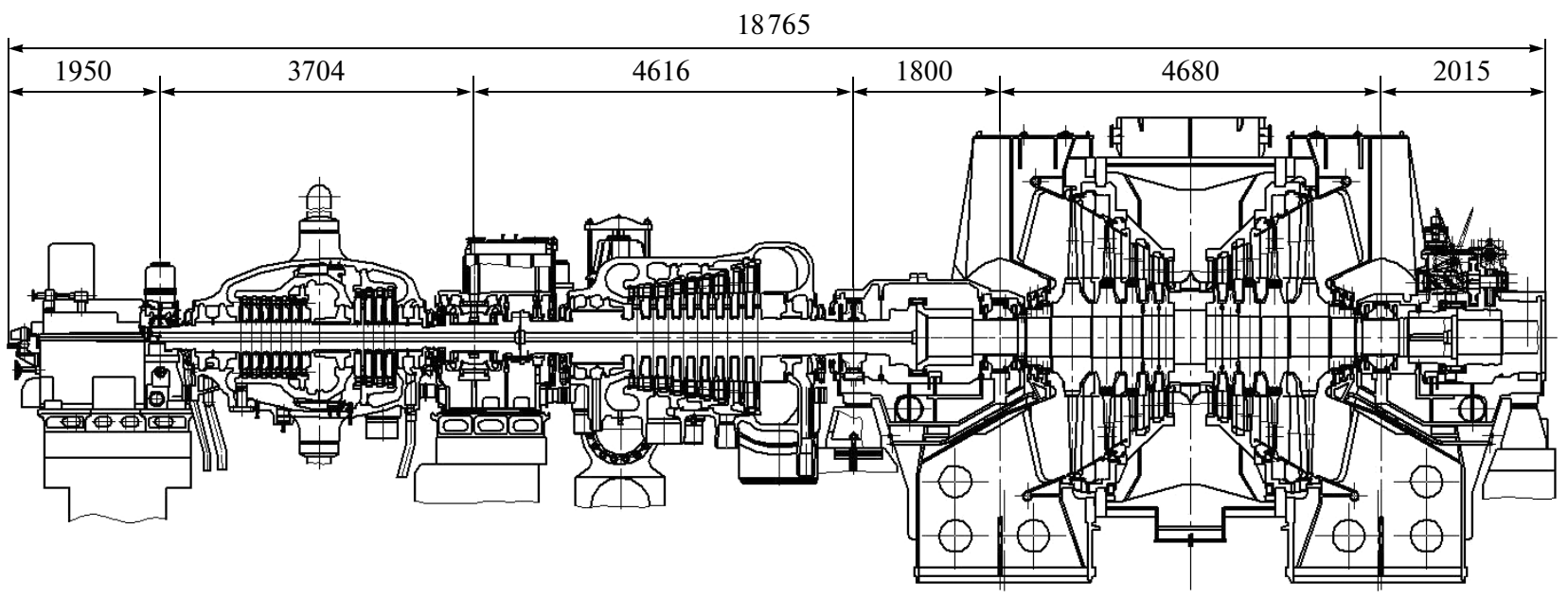

Fig. 5. The K-300-12.4 steam turbine.

pressure, $\mathrm{MPa}$.

temperature, ${ }^{\circ} \mathrm{C}$...

flowrate, $\mathrm{t} / \mathrm{h}$

Parameters of low-pressure steam:

pressure, MPa...

temperature, ${ }^{\circ} \mathrm{C}$

flowrate, $\mathrm{t} / \mathrm{h}$.

Parameters of steam upstream of the LPC after mixing with low-pressure steam:

pressure, $\mathrm{MPa}$.

temperature, ${ }^{\circ} \mathrm{C}$

315.3

flowrate, $\mathrm{t} / \mathrm{h}$.

808.0

Steam pressure in the condenser (with clean heattransfer surfaces), $\mathrm{kPa}$.

The HPC has a throttle-type steam admission system without a control stage. Intermediate-pressure steam is supplied to the "cold" steam reheat leg, and low-pressure steam is supplied to the IPC-LPC crossover pipes. The HPC casing has a similar design with that of the T-125-12.8-12M turbine, and the IPC casing has a similar design with the IPC-1 casing of the T-250/300-23.5 turbine. The LPC casing has a welded design, with five stages in each flow. The last-stage rotor blades have a height of $940 \mathrm{~mm}$. At present, the previously used low-pressure part blade system is being optimized at UTZ for the operating conditions of this condensing turbine. A new last stage with 1080$\mathrm{mm}$-long steel rotor blades is being developed within the framework of works on improving the low-pressure part in order to reduce losses with outlet velocity.

If an order is received for this turbine, UTZ specialists will be ready to develop a working project for it within a short period of time.

All turbines are fitted with a modern microprocessor electrohydraulic control and protection system consisting of three main parts: a hydraulic part (EHCPS), electric part (EPCPS), and electrohydraulic converters (EHCs) performing the functions of converting electric control signals produced by the EPCPS into the input hydraulic signals for the EHCPS.

All functions relating to governing, closed-loop control, and protection of the turbine itself are implemented in the EPCPS, which includes the following components:

(i) a control cabinet with a redundant controller;

(ii) an interruptible power supply cabinet;

(iii) an engineering station;

(iv) a set of sensors required for operation of the EHCPS (including the rotation sensors installed in the front bearing unit for measuring the turbine rotation frequency via six independent channels); and

(v) single-turn electric drives (an electric singleturn actuator).

Control of the turbine is performed from a workstation within the composition of the automated process control system.

Thus, modern steam turbines of a few standard sizes for CCPs with capacities ranging from 90 to $900 \mathrm{MW}$ are available at UTZ, which is sufficient for fully meeting the needs of customers in constructing and retrofitting thermal power stations for fulfilling the investment program aimed at developing the power industry of Russia.

\section{REFERENCES}

1. G. D. Barinberg, A. E. Valamin, P. V. Kogan, and A. Yu. Kultyshev, "Cogeneration steam turbines for combined-cycle installations of 170-230 MW," Therm. Eng., No. 6, 478 (2008). 
2. G. D. Barinberg, A. E. Valamin, and A. Yu. Kultyshev, "Prospective steam turbines for combined-cycle plants," Therm. Eng., No. 8, 629 (2008).

3. G. D. Barinberg, A. E. Valamin, and A. Yu. Kultyshev, "Steam turbines of the Ural Turbine Works for advanced projects of combined-cycle plants," Therm. Eng., No. 9, 721 (2009).

4. G. D. Barinberg, A. E. Valamin, A. Yu. Kultyshev, and T. Yu. Linder, "Steam turbines of the Ural Turbine Works for combined-cycle plants," Therm. Eng., No. 9, 728 (2009).

5. G. D. Barinberg, A. E. Valamin, A. Yu. Kultyshev, et al., "New draft projects of steam turbines for combinedcycle plants," Therm. Eng., No. 1, 15 (2011).

6. G. D. Barinberg, A. E. Valamin, A. A. Gol'dberg, et al., "The T-53/67-8.0 cogeneration steam turbine for the PGU-230 combined-cycle plant at the Minsk TETs-3 cogeneration station," Therm. Eng., No. 8, 642 (2008).

7. A. E. Valamin, A. Yu. Kultyshev, V. N. Bilan, et al., "The cogeneration steam turbine of the T-63/76-8.8 type foe a series of PGU-230 combined cycle power plants," Therm. Eng., No. 12, 883 (2012).

8. A. E. Valamin, A. Yu. Kultyshev, V. N. Bilan, et al., "The cogeneration steam turbine of the T-40/50-8.8 type for the combined cycle power plant PGU-115," Therm. Eng., No. 12, 893 (2012).

9. A. E. Valamin, A. Yu. Kultyshev, A. A. Gol'dberg, et al., "The cogeneration steam turbine of the Tp-35/40-8.8 type," Therm. Eng., No. 12, 900 (2012).

10. G. D. Barinberg, A. E. Valamin, A. A. Gol'dberg, et al., "A T-113/145-12.8 cogeneration steam turbine for the PGU-410 combined-cycle plant at the Krasnodar cogeneration station," Therm. Eng., No. 9, 732 (2009).

11. "The general scheme for placement of electric power facilities up to 2020," Elektr. Stn., No. 9, 4-17 (2008).

12. "Supporting the investment program with equipment and materials," Elektr. Stn., No. 9, 18-24 (2008).

13. G. D. Barinberg, Yu. A. Sakhnin, and A. A. Ivanovskii, "A turbine flow path annular chamber for mixing steam flows," RF Patent No. 2386039, IPC F01D 9.02.

Translated by $V$. Filatov 